\title{
MOBILITAS MURSYID CUM-AKTIVIS DALAM TRADISI TAREKAT
}

\author{
Rizqa Ahmadi, ${ }^{1}$ Wildani Hefni ${ }^{2}$ \\ ${ }^{1}$ Institut Agama Islam Negeri Tulungagung - Indonesia, \\ 2Institut Agama Islam Negeri Jember - Indonesia \\ e-mail: 1rizqa.uns@gmail.com; 2wildani91@gmail.com
}

\begin{abstract}
This article elaborates on the role and movement of murshid as an informal institution in the tarekat, which is at the same time an integral part of the Sufism tradition. By using a socio-historical approach, this article identifies the intellectual movement of murshid in reproducing and reformulating strong beliefs as a connector of scientific transmission traditions (sanad), which are convened into two categories. First, the movement that interprets murshid activism in terms of their characteristics, such as their thoughts that play its function in regulating some religious aspects, especially as a reference for the followers. Second, the murshid movement that links a structure into social functions, for example creating, disseminating, and carrying out culture. Murshid in this category is identified as the holder of scientific sanad that have vertical mobility to save the world so that it does not become a prison for individuality. This category of murshid charisma can be the foundation of the followers of the tarekat to avoid a lot of false information, the spread of hoax news from social media, and various other noises in this post-truth era.
\end{abstract}

\begin{abstract}
Abstrak: Artikel ini menguraikan peran dan gerak mobilitas mursyid sebagai institusi informal dalam tarekat sekaligus bagian integral dalam tradisi tasawuf. Dengan menggunakan pendekatan sosio-histrosis, artikel ini mengidentifikasi mobilitas intelektual mursyid dalam mereproduksi dan mereformulasi kepercayaan yang kuat sebagai penyambung sanad keilmuan yang kemudian dikelompokkan menjadi dua kategori. Pertama, mobilitas yang menginterpretasikan aktivis dalam kerangka karakteristik personal, seperti mobilitas mursyid yang menjadikan berpikir sebagai kerja sekaligus memainkan fungsinya dalam mengatur segala hal, utamanya menjadi rujukan dari para pengikut. Kedua, mobilitas yang mengaitkan suatu struktur dengan fungsi sosial, misalnya menciptakan, menyebarluaskan, dan menjalankan kebudayaan. Mursyid dalam kategori ini diidentifikasi sebagai pemegang sanad keilmuan yang memiliki mobilitas vertikal untuk menyelamatkan dunia agar tidak menjadi penjara bagi individualitas. Karisma mursyid kategori kedua ini dapat menjadi tumpuan para pengikut tarekat untuk terhindar dari gencarnya informasi yang dusta, berita bohong dari media sosial, dan pelbagai kegaduhan lainnya di era pascakebenaran.
\end{abstract}

Keywords: murshid; mobility; activist; tarekat 


\section{A. Pendahuluan}

Di tengah arus globalisasi yang semakin lama dirasakan menggerogoti nilai spritualitas, dunia tasawuf mengalami peningkatan. Tingginya spritualitas keimanan menjadi penanda dari maraknya kajian tasawuf yang mengalami perkembangan pesat ${ }^{1}$ Pada hakikatnya, tasawuf adalah ajaran penyempurna dalam spiritualitas Islam. Ia merupakan aktualisasi satu dari tiga pilar penting dalam Islam, yakni ihssān. ${ }^{2}$

Ajaran tasawuf yang melekat sebagai citra dasar manusia telah membumi di tengah-tengah masyarakat. Tema-tema tentang tasawuf atau spiritualitas dalam pengertian yang lebih umum, banyak dibicarakan oleh elemen masyarakat di pelbagai kesempatan, baik formal maupun non formal. Dari masyarakat kelas bawah, menengah, hingga elit, masing-masing sampai pada satu kesimpulan bahwa bertasawuf menjadi sebuah kebutuhan primer. Bahkan ada yang secara rigid mengikuti tasawuf dengan melakukan bai'at (sumpah) kepada mursyid (pembimbing) tarekat. Fenomena seperti ini biasanya terdapat di desadesa ataupun masyarakat dengan kultur religius kuat. Ada pula yang mengambil sisi-sisi praktis dari ajaran tasawuf, seperti zikir, pembersihan jiwa (tazkiyyatalnafs), terapi untuk kesehatan dan sejenisnya. ${ }^{3}$ Model kedua ini biasa terjadi pada masyarakat urban, yang kemudian oleh Julia D. Howell disebut sebagai urban sufism, ${ }^{4}$ yaitu fenomena sufisme pada masyarakat perkotaan.

Model bertasawuf dari dua tipe masyarakat di atas tidak mutlak. Perkembangan masyarakat yang dinamis dan pertukaran informasi yang begitu cepat bisa jadi berlaku sebaliknya. Tarekat-tarekat yang semula identik dengan masyarakat desa, kini juga diikuti oleh kaum urban. Begitu juga tasawuf praktis

${ }^{1}$ Alwi Shihab, Akar Tasawuf di Indonesia: Antara Tasawuf Sunni dan Tasawuf Falsafi (Tangerang: Pustaka IIMaN, 2009), ix.

${ }^{2}$ Dimensi pertama adalah syariah, kedua adalah aqidah dan ketiga adalah ihsan. Ihsan merupakan sikap dan perilaku dari seseorang yang benar-benar menghamba kepada Tuhannya dengan segala bentuk budi pekerti luhur terhadap sesama manusia dan sesama makhluk Tuhan. Penghambaan ini kemudian mengantarkan seseorang pada sebuah jalan yang disebut tasawuf. Lihat: Ahmad Syafii Mufid, Tangklungan, Abangan dan Tarekat: Kebangkitan Agama di Jawa Uakarta: Yayasan Obor Indonesia, 2006), 3.

${ }^{3}$ Annemarie Schimmel, al-Ab'ad al-Ṣüfiyyah fi al-Islām wa Tārikh Taṣawwuf, terj. Muhammad Ismail Sayyid dan Ridha Hamid Qutb (Jerman: Al-Jamal, 2006), 35-37.

4Julia Day Howell, "Indonesia's Urban Sufis: Challenging Stereotypes of Islamic Revival," ISIM Newsletter 6, no. 1 (2000): 17, /hdl.handle.net/10072/58807. 
yang awalnya diinisiasi oleh kelompok menengah di perkotaan telah menjadi magnet yang memikat masyarakat pesisir, pinggiran, maupun pedesaan.

Perkembangan pesat dunia tasawuf dapat dilihat dari kecenderungan masyarakat yang haus tentang dunia spiritual. Faktor yang sangat besar dalam hal ini adalah perasaan hampa dan jiwa yang kosong yang kemudian mendorong masyarakat untuk aktif dan berpartisipasi dalam aktifitas tasawuf antara lain menyucikan jiwa, mengosongkan hati dari permasalahan dunia, dan memasrahkan diri kepada Tuhan. Fakta tersebut didorong oleh idealisme yang perlahan terkoyak dan terancam di ruang publik dengan aneka tsunami informasi dan himpitan sosial media. Situasi ini kemudian dijelaskan dengan komprehensif oleh Fuller sekaligus mengungkap bahwa istilah post-truth (pasca kebenaran) pertama kali diperkenalkan oleh Oxford Dictionaries. ${ }^{5}$

Pada era pasca kebenaran, banyak orang yang terpapar hoaks, ujaran kebencian, dan konten negatif secara berantai hanya karena tidak arif dan kritis menggunakan media sosial sebagai sarana berkomunikasi dan berbagi informasi. Masifnya semburan dusta (firehose of false) yang menyeret dalam dark social (kegelapan sosial) telah berdampak pada kedengkian dan permusuhan. ${ }^{6}$

Fenomena post-truth terus merajalela dan memancing emosi. Daya transformasi media sosial dibayang-bayangi oleh ketakutan akan pemelintiran kebenaran. Dalam konteks ini, dunia tasawuf menjadi pelarian masyarakat untuk bertahan dari pertempuran dunia. Tasawuf kemudian menjadi pelarian yang befungsi sebagai faktor integrasi masyarakat berdasar teori dan konsep antropologi agama. Sebagaimana Durkheim menyebut bahwa agama dalam pandangan ilmu-ilmu sosial memiliki fungsi integratif yakni mempersatukan kembali masyarakat melalui upacara-upacara keagamaan. ${ }^{7}$

Eksodusnya masyarakat dalam dunia tasawuf di era pasca kebenaran seperti dijelaskan di atas terkonfirmasi pada upacara keagamaan dalam tasawuf yang disebut dengan istilah tarekat sebagai wadah untuk pembersihan jiwa.

5Steve Fuller, Post Truth: Knowledge as Power Game (London: Anthem Press, 2018), 7.

${ }^{6}$ Hannah L Cook, "Liability: Avoiding the Lanham Act and the Right of Publicity on Social Media," The University of Chicago Law Review 83, no. 1 (2016): 457-502.

${ }^{7}$ Emile Durkheim, The Division of Labor in Society (Illinois: The Free Press of Glencoe, 1960), 61; Lihat: Eugen Schoenfeld dan Stjepan G. Mestrovic, "Durkheim's Concept of Justice and Its Relationship to Social Solidarity," Sociological Analysis 50, no. 2 (1989): 111-27, https://doi.org/ $10.2307 / 3710982$. 
Tasawuf dan tarekat tidaklah sama. Secara sederhana, dapat disimpulkan bahwa tasawuf lebih umum dari pada tarekat. ${ }^{8}$ Tarekat adalah bagian dari tasawuf, sedangkan tasawuf belum tentu berwujud dalam bentuk tarekat. ${ }^{9}$ Pada level tarekat inilah, masyarakat menggantungkan diri untuk pasrah terhadap apa yang diajarkan di dalamnya.

Dalam sejarahnya, tarekat memiliki kontribusi penting. Ia tidak hanya sebagai institusi pendidikan spiritual tetapi juga sebagai kantong-kantong gerakan perubahan sosial. Pada mulanya, tarekat bertujuan untuk mendidik mental spiritual dan membersihkan diri untuk sampai pada tingkatan (maqām) tertentu. Tarekat banyak berbicara tentang maqām untuk sampai pada suatu keadaan $(a h w \bar{a} l)$ yang dianugerahkan oleh Tuhan. Pada perkembangan selanjutnya, tarekat menjadi persaudaraan yang tersusun secara sistematis dan struktur. Ajarannya menjadi lebih sistematis dengan model kurikulum, serta terdapat ikatan dan hubungan yang intens antara guru dan murid dengan kontrak spiritual. Selain itu, dalam ranah sosial maupun politik ordo sufi (sebutan lain dari tarekat) sebagaimana disebutkan Tirmingham, menjadi sarana perjuangan dan pergerakan. ${ }^{10}$ Fenomena tarekat Sanūsiyyah dan tarekat Tijāniyyah di Afrika, tarekat Naqshabandiyyah di Turki, dan tarekat Khalwatiyyah di Indonesia adalah di antara contoh konkret kontribusi tarekat dalam ranah sosial politik.

\footnotetext{
${ }^{8}$ Tasawuf secara natural lahir dan tumbuh bersama dengan ajaran Islam. Meski dikaitkan dengan tradisi kehidupan asketik-ruhani Kristen atau ajaran gnosticism neo-platonisme, ataupun yang lain, namun sufisme adalah salah satu doktrin ajaran Islam. Hal ini dipertegas oleh Seyyed Muhammad Rastgoo Far dan Mahdi Dasht Bozorgi dengan menunjukkan keterikatan kuat tasawuf dengan norma Islam baik dalam al-Qur'an maupun hadis. Asumsi-asumsi seputar sumber non-Islam dari tasawuf secara otomatis terbantah dengan sendirinya. Kemiripan model ritual dan praktikpraktik asketik tidak secara otomatis menjadikan tasawuf tertuduh melakukan reproduksi ajaran. Lihat: Seyyed Muhammad Rastgoo Far dan Mahdi Dasht Bozorgi, "The Origin of Mysticism and Sufism in Hadith," Religious Inquiries 2, no. 3 (2013): 103-17.

${ }^{9}$ Awal kemunculan tasawuf tidak dalam format tarekat atau ordo-ordo sufi. Tasawuf lahir dengan model praktikal individual sebagai bentuk perjalanan ruhani bukan teoritikal praktis dengan aturan dan tata cara tertentu. Tasawuf pada awal perkembangannya sebagai bentuk peneladanan atas cara hidup keruhanian Rasulullah. Orang-orang yang meniru cara hidup Rasulullah ini disebut dengan ahl al-șuffah. Ahl al-șuffah adalah di antara sahabat Nabi yang kurang mampu yang menempati salah satu sisi dari masjid Nabawi, diantaranya Abu Dzar al-Ghifari. Salman al-Farisi, Uwais al-Qarani. Lihat: Ahmad S. Dallal, "Sufism, Old and New: The Multiple Faces of the Spirit," dalam Islam without Europe: Traditions of Reform in Eighteenth-Century Islamic Thought (Chapel Hill: University of North Carolina Press, 2018), 94-139, https://doi.org/10.5149/northcarolina/ 9781469641409.003.0004.
} 1998), 2.

10 J. Spencer Trimingham, The Sufi Orders in Islam (Oxford, New York: Oxford University Press, 
Keberhasilan persaudaran sufi baik dalam mendidik jiwa ataupun dalam menyuarakan perubahan tidak dapat dilepaskan dari keberadaan seorang mursyid (pembimbing) atau syaikh (pemimpin). Mursyid sebagi figur secara normatif memiliki otoritas yang dinamis. Bermula secara otoritatif menjadi rujukan laku spiritual para murid, kemudian menjadi instruktur dalam hal sosial dan kemasyarakatan. Apa yang diinstruksikan oleh sang mursyid terlegitimasi secara sosial sebagai kebenaran dan masyarakat akan mematuhinya. Mursyid menjadi ilustrasi kedahsyatan yang di dalamnya bertumpu sebuah harapan.

Artikel ini mendedah mobilitas mursyid dalam tarekat dalam konteks interrelasi sosial dan konstruk manajemen yang diperankan. Dalam artikel ini pula dijelaskan ruang gerak mursyid yang begitu luas untuk mengatur dan mengontrol perjalanan sebuah institusi yang dipimpinnya, yang oleh Mubarak Ali disebut sebagai kerajaan spiritual (the spiritual kingdom of the saints). ${ }^{11}$ Bagaimanakah historisitas mursyid dalam tradisi tarekat dan mengapa mereka memiliki dominasi legitimasi yang otoritatif dalam hal spiritual maupun sosial hingga mampu memberikan karisma inspirasional bagi masyarakat yang eksodus pada dunia tarekat di era pasca kebenaran? Dalam artikel ini, peneliti melakukan penelusuran dalam al-Qur'an, hadis maupun istilah para sufi, kemudian dilanjutkan dengan sejarah singkat kelahiran dan perkembangan tarekat, serta secara lebih komprehensif melihat dan menganalisis gerak mobilitas mursyid dalam menjalankan otoritas keagamaan di era post-truth sebagaimana digambarkan di atas.

\section{B. Mursyid dalam Terminologi al-Qur'an dan Hadis}

Dalam telaah kesarjanaan, tasawuf sebagai sebuah ajaran agama yang bercorak kerohanian (esoteris), belum ditemukan pada awal kelahiran Islam. Akan tetapi spiritnya telah ada bersama lahirnya Islam. Untuk memastikan hal itu, penelusuran kata mursyid sangat tepat dengan merujuk pada sumber normatif Islam yaitu al-Qur'an dan Hadis.

Kata mursyid di dalam al-Qur'an hanya ada satu yakni pada QS. al-Kahfi [18]: 17. Adapun yang lain berbentuk lain dari kata tersebut yang merupakan bagian dari derivasinya, seperti kata yarshudūn dalam al-Baqarah [2]: 186, kata

11Mubarak Ali, The Ulema, Sufis, and Intellectuals (Lahore: Fiction House, 2005), 80.

JURNAL THEOLOGIA — Volume 30, No. 2, December 2019 
al-rushdu terdapat pada tiga tempat, yaitu QS. al-Baqarah [2]: 256, QS. al-A'raf [7]: 146, QS. al-Jin [72]: 2. Sedangkan kata rushdan dalam QS. al-Nisa [4]: 6 dan QS. al-Kahfi [18]: 66, kata rushdah dalam QS. al-Anbiya [21]: 51; kata rashadā terdapat pada QS. al-Kahfi [18]:10 dan 24, QS. al-Jin [72]: 10, 14, dan 21; kata alrasyād pada QS. Ghafir [40]: 29 dan 38; dan kata al-rāshidūn dalam QS. alHujurat [49]: 7; serta kata rashīd dalam QS. Huud [11]: 78, 87, dan 97.12

Sedangkan dalam hadis Nabi, kata mursyid justru hanya terdapat pada redaksi suatu hadis tentang sifat dari seorang wali dalam hal pernikahan, $l \bar{a}$ nikāha illā bi walyyin murshidin wa shāhidai 'adlin.13 Mursyid dalam konteks hadis tersebut tidak sama maknanya dengan mursyid dalam pengertian ahli tasawuf. Mursyid yang dimaksudkan dengan makna kebahasaan, yaitu penunjuk.

Dengan demikian, baik di dalam al-Qur'an maupun hadis, kata mursyid tidak secara eksplisit merujuk pada makna mursyid sebagaimana istilah tersebut dipakai dalam tasawuf pada perkembangan selanjutnya. Kata mursyid lebih merujuk pada makna yang lebih umum dan substantif, yakni orang yang menunjukkan pada kebenaran, bahkan beberapa ayat menunjukkan bahwa mursyid diasosiasikan sebagai petunjuk dari Allah.

Berbeda halnya jika melihat penjelasan dan penafsiran para sufi, seringkali istilah mursyid dinisbahkan kepada hadis Nabi yang diriwayatkan 'Irbādh bin Sāriyah: 'Alaikum bi sunnatī wa sunnati al-khulafầ' al-rāshidīn al-mahdiyyīn 'aḍdū 'alaihā bi al-nawājidh. ${ }^{14}$ Oleh para sufi, khulāfā' al-rāshidūn tidak hanya dimaknai dengan empat sahabat setelah Nabi tetapi para penerus yang terdiri dari para ulama yang mendapatkan petunjuk dari gurunya dan gurunya dari gurunya hingga sampai kepada keempat sahabat tersebut. Dalam pandangan para sufi, khalifah akan terus ada sampai hari kiamat. Di setiap masa terdapat para rasul penerus kenabian. Secara lebih khusus, mereka adalah wali mursyid (syaikh) atau khalifah dalam tradisi tarekat.

Meskipun tafsir sufi terkenal dengan tafsir ishāri (tafsir intuitif) yang tentu berbeda dengan umumnya tafsir al-Qur'an, namun peneliti belum menemukan

${ }^{12}$ Muhammad Fu'ād 'Abd al-Bāqī, al-Mu'jam al-Mufahras li Alfāz al-Qur'ān al-Karīm (Kairo: Dār al-Hadīth, 1364), 394.

${ }^{13}$ Muḥammad ibn Idrīs al-Shāfi'ì, al-Musnad (Beirut: Dār al-Kutub al-'Ilmiyyah, 1400), 220.

${ }^{14} \mathrm{Abū} \mathrm{'Īsā} \mathrm{al-Tirmidhī,} \mathrm{Sunan} \mathrm{al-Tirmidhī} \mathrm{(Beirut:} \mathrm{Dar} \mathrm{al-Fikr,} \mathrm{2005),} \mathrm{h.} 2600$. 
secara eksplisit penjelasan tentang arti mursyid dalam QS. al-Kahfi [18]: 17 dengan makna seperti di atas. Peneliti juga telah melacak beberapa kitab tafsir sufistik, seperti Rūḥ al-Ma'āni karya Imam al-Alusi, al-Kashshāf al-Zamakhsyari, Mafātịh al-Ghaib Fakhruddīn al-Rāzi, Tafsir Syaikh 'Abd al-Qādir al-jillani, dan Lațāif al-Ishārātal-Qushairi.

Penjelasan tentang penafsiran mursyid tarekat dalam kalimat waliyyan murshidā dalam QS. al-Kahfi [18]: 17 ditemukan dalam penjelasan Kharisuddin Aqib. Menurutnya, kata waliyyan murshidā dimaknai dengan wali mursyid sebagaimana dalam tradisi tarekat. Mereka adalah sosok yang dapat memberikan petunjuk dalam perjalan spiritual. Menurutnya, ada tiga jenis manusia. Pertama, al-muhtadī yaitu orang yang mendapatkan petunjuk, kedua, al-muḍil adalah orang yang tersesat, dan ketiga wali murshid yang bertugas membimbing umat dan pelanjut tugas kerasulan. Ia juga menegaskan bahwa wali mursyid tergolong dari wali yang mendapat amanah dari gurunya.

Dalam konsepsi Aqib, wali terdiri dari dua yakni wal̄ murid, dan walī murād. Yang pertama, ia menjadi wali karena usaha yang dilakukan dengan mujāhadah dan riyāḍah sehingga sampai pada level maksimal. Sedangkan yang kedua, mereka menjadi wali di luar dari kehendak dirinya sendiri melainkan karena kehendak Allah. Wali mursyid termasuk ke dalam kategori yang pertama. Hakikatnya wali mursyid adalah khalifah dari gurunya dan gurunya adalah khalifah dari gurunya dan seterusnya hingga Rasulullah. Maka Aqib menegaskan bahwa kedudukan wali mursyid adalah sebagai penerus para Nabi dan secera otomatis mereka memiliki sifat kāmilun mukammilun, yaitu sempurna lagi menyempurnakan. ${ }^{15}$

Meskipun tidak secara eksplisit istilah mursyid tertera di dalam al-Qur'an maupun hadis Nabi, namun banyak ayat al-Qur'an dan hadis Nabi yang secara implisit menegaskan pentingnya keberadaan seorang guru dalam mempelajari dan menjalankan agama. Mereka adalah orang-orang pilihan yang mendapat titah untuk mencerahkan umat dan memberikan petuah dan wawasan keagamaan. Ayat-ayat al-Qur'an dan hadis yang membicarakan hal tersebut biasanya dijadikan legitimasi dalam tradisi dan ritual kaum tarekat.

${ }^{15}$ Abduloh Kharisuddin Aqib, "Kriteria dan Persyaratan Seorang Mursyid," Metafisika Center, 2018, http://www.metafisika-center.org/2018/03/wali-mursyid.html.

JURNAL THEOLOGIA — Volume 30, No. 2, December 2019 


\section{Formasi Genealogis Organisasi Tarekat}

Telah banyak sarjana melakukan penelitian tentang awal kemunculan dan perkembangan tarekat, seperti Trimingham, ${ }^{16}$ Annemarie Schimmel, 17 Nicholson, ${ }^{18}$ Louis Masignon, ${ }^{19}$ A. J. Arberry, ${ }^{20}$ dan lainnya. Dari temuan mereka, benang merah yang dapat ditarik bahwa, tarekat telah mengalami perkembangan yang dinamis. Titik permulaannya dapat dilacak dari silsilah tasawuf yang dinisbahkan kepada 'Alī ibn Abì Ṭālib. 'Alī adalah satu-satunya sahabat yang paling zuhud dan memiliki keilmuan batin melampau sahabat yang lain. Ia juga diyakini oleh para sufi sebagai sahabat yang mendapatkan wasiat dari Rasul secara langsung tentang ajaran spiritualitas. ${ }^{21}$

Dari perkembangan itu, dalam dunia tasawuf kemudian berkembang tarekat yang lahir bermula dari ketertarikan para murid untuk mencari guruguru spiritual yang memiliki kelebihan. Pada perkembangan selanjutnya, tarekat telah bergeser dari orientasi awal, yakni dari institusi spiritual semata menjadi institusi sosial keagamaan. ${ }^{22}$ Ditandai dengan alih fungsinya zāwiyyah, ribāt, khānāqah dari tempat untuk 'uzlah menjadi tempat untuk merencakan dan melakukan berbagai kegiatan sosial.

Dari konteks formasi sosio-historis tarekat, istilah mursyid secara genealogis pertama kali dipakai pada abad ke-2 Hijriyyah, bersama mulai tumbuhnya tradisi berguru kepada orang-orang yang dianggap ahli ibadah dan zuhud yang tinggal di tempat-tempat khusus. Murshid, murād, shaikh atau pir'i memiliki hubungan yang begitu intens dengan murid-muridnya atau yang dikenal dengan istilah șuhbah. $^{23}$

${ }^{16}$ Trimingham, The Sufi Orders in Islam.

${ }^{17}$ Annemarie Schimmel, Mystical Dimensions of Islam (Carolina: The University of North Carolina Press, 1975).

${ }^{18}$ Reynold A. Nicholson, The Mystics of Islam (London: Routledge and Kegan Paul, 1975).

${ }^{19}$ Louis Massignon, Halläj: Mystic and Martyr, terj. H. Mason (Princetown: Princeton University Press, 1994).

${ }^{20} \mathrm{~A}$. J. Arberry, The Doctrine of The Sufis (Cambridge: Cambridge University Press, 1935).

${ }^{21}$ Ihsan Ilāhi Zāhir, al-Taṣawwuf: al-Mansha wa al-Mașdar (Lahore, Pakistan: Idārah Tarjaman al-Sunnah, 1986), 150-53.

${ }^{22}$ Agus Riyadi, "Tarekat sebagai Organisasi Tasawuf (Melacak Peran Tarekat dalam Perkembangan Dakwah Islamiyah)," Jurnal al-Taqaddum 6, no. 2 (2014): 359-85, https://doi.org/10.21580/at.v6i2.716.

${ }^{23}$ Suhbah adalah hubungan antara murid dan guru sprittual di dalam tradisi tarekat. Hubungan keduanya bertujuan untuk mempermudah tujuan sampai seorang murid kepada maqām 
Para sarjana, di antaranya 'Abd al-Mun'în al-Hiifnī menyebutkan bahwa dalam format sederhana, tarekat telah ada kira-kira abad ke-3 Hijriyah ditandai dengan munculnya guru-guru spiritual seperti Junaid al-Baghdadi (w. $297 \mathrm{H}$ ), Sarry al-Saqați (w. 251 H), dan Abū Ḥusain al-Nūri (w. 295 H). ${ }^{24}$ Salah satu yang mempertegas akan hal ini adalah Tirminghams. Menurutnya, dua tokoh sufi besar dari daratan Iraq yang dipelopori oleh Junaid al-Baghdadi dan dari daratan Khurasan yang diwakili oleh Abū Yāzid Țaifur al-Bustami (w. 260) adalah yang sangat masyhur sebagai syaikh, sebutan lain dari mursyid, dalam suatu komunitas tarekat. ${ }^{25}$ Dalam sejarahnya, tarekat menjadi terlembaga dengan berkembangnya persaudaraan tarekat dalam struktur organisasi yang sistematis pada abad ke-5 Hijriyah, ditandai dengan berkembang pesatnya tarekat Qadiriyah yang dinisbahkan pada Shaikh 'Abd al-Qādir al-Jilani dan Rifa'iyyah yang dinisbahkan kepada Abu al-Abbās Aḥmad ibn 'Alī al-Rifa'i.

Sedangkan menurut Arberry, abad ke-6 Hijriyah adalah abad saat tradisi tasawuf dalam model tarekat tersebar luas. Shaikh Muhyi al-Dīn 'Abd al-Qādir alJilani (w. 561) adalah salah satu tokoh sufi yang cukup tenar kala itu. Pasca meninggalnya al-jillani, para pengikutnya menambahkan di akhir namanya dengan Qadirī. Salah satu bukunya yang menjadi rujukan para pengikut tarekat Qadiriyah adalah al-Ghunya li-Ṭālibi Ṭarīq al-Haqq Seorang sufi di abad yang sama yang juga memiliki pengaruh para pengikutnya dalam bentuk tarekat adalah Shihāb al-Dīn 'Umar 'Abdullāh al-Suhrawardi (539-632 H/1144-1234 M). Karyanya yang fenomenal adalah 'Awārif al-Ma'ārif yang juga memiliki pengaruh kuat dalam ajaran tarekat. Kemudian, juga termasuk ke dalam kategori sufi-sufi awal ternama adalah Nür al-Dīn Ahmmad ibn 'Abdillāh al-Shadhili (593-656 H/1196-1258 M). Salah satu pengikutnya yang sampai hari ini populer adalah Syaikh Ibn 'Athaillah al-Sakandari (w. $709 \mathrm{H}$ ) penulis kitab alHikām. ${ }^{26}$

(tingkatan) spiritual tertentu. Keberedaan guru spiritual dalam șuhbah sangat penting. Guru menjadi mediator pada saat melakukan zikir atau melakukan khalwat. Bahkan pada keadaan tertentu seorang murid harus dapata membayangkan kehadiran dan keberadaan guru dalam kondisi apapun. Keadaan ini diyakini akan memudahkan murid untuk dapat wușūl (sampai) kepada Tuhan.

24‘Abd al-Mun'̄n al-Hiifnī, al-Mausū’ah al-Șūfiyyah (Kairo: Maktabah Madbūīi, 2006), 1111.

${ }^{25}$ Trimingham, The Sufi Orders in Islam, 4.

${ }^{26}$ A. J. Arberry, Sufism: An Account of the Mystics of Islam (New York: Routledge, 1950), 85-87.

JURNAL THEOLOGIA — Volume 30, No. 2, December 2019 
Menurut Abu Bakar Atjeh, kekeluargaan dalam tarekat pada awalnya diminati oleh orang awam, umumnya orang-orang fakir (Persia: darwish) yang tidak memiliki banyak harta. ${ }^{27}$ Mereka tidak mengharapkan imbalan apa-apa kecuali hanya untuk beribadah di tempat tempat tertentu yang disebut dengan ribāț²8 (Persia: changah).

\section{Gerak Mobilitas dan Otoritas Mursyid}

Mursyid adalah jabatan spiritual yang diperoleh secara turun temurun melalui jalur silsilah hingga sampai kepada Nabi. Prinsip dari jabatan ini adalah adanya kewalian yang dianggap sakral sebagaimana diutusnya Nabi maupun Rasul. Bedanya jika Rasul diperintahkan untuk memberitahukan, sedangkan wali justru untuk menyembunyikan. Jika Nabi memiliki mu'jizat maka wali memiliki karamah. Sebagaimana Nabi disifati sebagai ma'șūm, sementara wali disebut mahfüz:.29 Bahkan, dalam pandangan Ibnu 'Arabi, kedudukan seorang mursyid dalam tarekat sama dengan kedudukan seorang Nabi pada masanya. ${ }^{30}$

Dalam dunia tarekat, seorang mursyid memiliki dua peran sekaligus. Peran pertama sebagai orang yang menunjukkan kepada kebenaran dan kesalehan akhlak, dan peran yang kedua sebagai perantara (wasilah) antara murid dan Allah. Seorang murid harus menggunakan perantara mursyid agar dapat sampai kepada Allah. ${ }^{31}$ Dapat dikatakan bahwa keberadaan mursyid sebagaimana keberadaan para Nabi dan Rasul yang sama sama berperan sebagai perantara ajaran Islam.

\footnotetext{
${ }^{27}$ Aboebakar Atjeh, Pengantar Ilmu Tarekat (Uraian tentang Mistik) (Solo: Ramadhani, 1985), 57.

${ }^{28}$ Ribāth dikenal sebagai tempat pondokan atau tempat singgah yang populer di Jazirah Arab, sedangkan di Khurasan biasa disebut khānāqah. Secara umum nama-nama tersebut sebagai tempat untuk melaksanakan ritual para sufi. Selain itu ada juga yang menyebut dengan zäwiyyah. Ribath yang disebut-sebut sebagai pondokan para sufi tertua adalah di pula Abbādān, Teluk Persia. Ribāt tersebut terkenal bersamaan dengan kemashuran salah seorang asketis bernama 'Abd al-Wāhid ibn Zaid (w. 177). Di berbagai tempat juga ditemukan tempat tempat yang semisal, seperti di Ramlah, ibu kota Palestina, dan Damaskus. Di Alexandria, sebuah organisasi (tāifa) yang telah menyebut kelompok mereka sebagai kelompok sufi juga ditemukan ribāth pada tahu $200 \mathrm{H}$. Lihat: Trimingham, The Sufi Orders in Islam, 5.
}

${ }^{29}$ Aqib, "Kriteria dan Persyaratan Seorang Mursyid."

${ }^{30}$ Yūsuf Khațtar Muhammad, al-Mausū'ah al-Yūsufiyyah fi Bayāni Adillat al-Süfiyyah (Damaskus: Dāral-Taqwā, 2003), 377.

${ }^{31}$ Atjeh, Pengantar Ilmu Tarekat (Uraian tentang Mistik), 59. 
Setidaknya ada dua otoritas yang dimiliki oleh seorang mursyid, yakni otoritas spiritual dan otoritas sosial. Jika otoritas spiritual sudah tentu melekat pada aktifitas tarekat karena memang hakikat tarekat adalah perjalanan spiritual. Adapun dalam hal sosial, seorang mursyid juga memiliki peran penting. Modal sosial yang dimiliki oleh persaudaran tarekat dengan ketaatan yang penuh kepada mursyid secara tidak langsung membawa ke ranah yang lebih praktis, seperti halnya sosial dan politik. Aktifitas dalam bentuk gerakan sosial politik yang digerakkan oleh para tokoh-tokoh sufi, telah terjadi di berbagai belahan dunia seperti Afrika, Sudan, Turki, dan juga Nusantara. Para mursyid tarekat menjadi motor penggerak perubahan sosial.

Sebagai contoh, tarekat Sanūsiyyah memiliki peran penting dalam membangun dinasti sufistik di daratan Afrika Utara. Muhammad bin 'Ali sebagai penggerak perubahan di Cyrenaica telah mengadopsi berbagai nilai-nilai mulia dalam tradisi sufisme. Mereka juga memiliki pertahanan yang cukup kuat untuk melawan berbagai kolonialisme Prancis dan Italia.32 Begitu juga dengan tarekat Tijāniyyah yang memiliki kontribusi penting dalam arus politik negara Senegal dan Nigeria. Bahkan, tarekat Naqshabandiyyah sempat menjadi oposisi pemerintahan Turki karena kontribusinya dalam melawan rezim yang sedang berkuasa. ${ }^{33}$ Fenomena tarekat di tanah Jawa pun juga senada, tarekat Qadiriyyah-Naqshabandiyyah berperan penting dalam melawan kolonialisme. ${ }^{34}$ Sedangkan tarekat Tijāniyah di Indonesia, menurut temuan Dudung, mengembangkan perlawanan melalui politik hijrah dalam rangka konsolidasi kekuatan rakyat melawan penjajah. Begitu juga tarekat Idrīsiyyah yang memberikan perlawanan berupa fisik dengan jaringan ketentaraan (hizbullāh) umat Islam. ${ }^{35}$

${ }^{32}$ Ghulam Shamas-ur-Rahman, "Book Review: Sanusìyah: A Study of A Revivalist Movement in Islam, by: Nicola A. Ziadeh, Leiden: E. J. Brill, 1958.Pages. 148," AI-Ehsan, no. 2 (n.d.): 21-27; Selengkapnya baca: Nicola A. Ziadeh, Sanüsìyah: A Study of A Revivalist Movement in Islam (Leiden: Brill Archive, 1958).

33Martin van Bruinessen, "Tarekat dan Politik," Pesantren, 1992, 4.

${ }^{34}$ Ajid Thohir, Gerakan Politik Kaum Tarekat: Telaah Historis Gerakan Politik Antikolonialisme Tarekat Qadiriyah-Naqsyabandiyah di Pulau Jawa, ed. Dedi Ahimsa Riyadi (Bandung: Pustaka Hidayah, 2002), 34.

35Abdurrahman Dudung, "Gerakan Sosial-Politik Kaum Tarekat di Priangan Abad XX" (Disertasi tidak dipublikasikan. PPs UIN Sunan Kalijaga, 2008), 266-67. 
Dalam konteks Indonesia, mursyid atau pemimpin tarekat memiliki peran cukup signifikan dalam sejarah sosial-politik, termasuk dalam memperjuangkan kemerdekaan dalam kerangka patriotisme kebangsaan. Sultan Hasanudin dan Syekh Yusuf al-Makasari memimpin pemberontakan Belanda di bagian tengah Nusantara. Sultan Agung Mataram, Sultan Ageng Tirtayasa Banten, Trunojoyo Madura, Iskandar Muda Aceh, Yang Dipertuan Raja Minangkabau, Pangeran Diponegoro dan Imam Bonjol berhasil mengoyak hegemoni kekuasaan kompeni Belanda. ${ }^{36}$ Tidak hanya itu, gelombang gerakan protes sosial dari kelompok tarekat yang dipimpin oleh seorang mursyid muncul di pelbagai kota. Tahun 1985 di Pekalongan, gerakan protes sosial di bawah komando KH. Ahmad Rifai Kalisalak. Di Cilegon Banten pada tahun 1988, pemberontakan kaum tani digerakkan oleh tokoh-tokoh tarekat seperti Kyai Abdul Karim dan Kyai Warsyid. Dalam konteks kekinian, Habib Lutfi bin Yahya Pekalongan adalah mursyid sekaligus Ketua Jami'iyyah Ahl Thariqah Mu'tabarah al-Nahdliyyah yang konsen pada pembangunan cinta bangsa atau nasionalisme. ${ }^{37}$ Gerak dan laku perjuangan Habib Lutfi sebagai mursyid mengajarkan keharmonisan, kedamaian, integrasi kebangsaan, dan penanaman nasionalisme.

Dari deretan peran yang disebutkan di atas, dapat dipahami bahwa mobilitas mursyid tidak terbatas pada persoalan ukhrawiyah-normatif dan parsial eskapis. Lebih dari itu, mursyid memainkan peran cum-aktivis dalam persoalan yang lebih luas, utamanya dalam konteks perubahan sosial. ${ }^{38}$ Tentu masih banyak lagi fakta-fakta lain yang memberikan gambaran bahwa para mursyid tarekat secara sosial memiliki otoritas yang sama kuat.

Dengan peran yang begitu penting, maka tidak setiap orang mampu dan dapat menyandang kedudukan tersebut. Mursyid harus memenuhi kriteria tertentu. Mereka adalah orang yang sudah sempurna suluk-nya (rijāl al-kamāl) dalam ilmu syari'at dan hakikat sesuai petunjuk al-Qur'an, sunnah, dan ijmā'. Maka, klaim kemursyidan seseorang tidak akan diakui jika hanya mengandalkan ego dan motif individu semata.

\footnotetext{
36Burhanuddin Daya, Agama Dialogis Merenda Dialektika Idealitas dan Realitas Hubungan Antar Agama (Yogyakarta: LKiS, 2004), 218.

${ }^{37}$ Imam Khanafi, "Tarekat Kebangsaan: Kajian Antropologi Sufi terhadap Pemikiran Nasionalisme Habib Luthfie," Jurnal Penelitian 10, no. 2 (2013): 336-58, https://doi.org/ 10.28918/jupe.v10i2.367.

38Peter D. Dwyer dan Monica Minnegal, "Theorizing Social Change," The Journal of the Royal Anthropological Institute 16, no. 3 (2010): 629-45, https://doi.org/10.2307/40926126.
} 
Dari sudut pandang pengikut tarekat yang memposisikan mursyid sebagai pemegang otoritas tunggal, mereka meyakini kedudukan mursyid begitu mulia karena para mursyid adalah wali yang mendapatkan karamah. ${ }^{39}$ Adanya keyakinan bahwa spiritualitas manusia akan tetap terjaga dengan mempertahankan kerajaan kewalian dengan berbagai struktur dan aturan tertentu sangat kuat menjadi bahan refleksi keseharian baik bagi mursyid maupun bagi pengikut tarekat Di satu sisi, mursyid dapat memainkan perannya yang cukup signifikan dalam mendirikan dan mempertahankan kerajaan spiritual karena bagi mursyid, kerajaan yang lain hanya bersifat sementara. Sedangkan kerajaan (kepemimpinan) ruhaniyah akan lestari hingga kapanpun. Sementara bagi pengikut, mursyid menjadi teladan yang diikuti segala titah dan perilakunya.

Untuk mempertahankan kekuasaan spiritual terus langgeng, maka dalam tradisi tarekat dikenal dengan adanya sumpah setia (bai'at). Dengan begitu hubungan antara guru dan murid akan terus terjaga sehingga ajarannya selalu ada yang melestarikan. Bai'at atau ijōzah (catatan berupa wasiat atau keterangan), khirqah (benda bisa berupa sehelai kain atau yang lain yang diberikan oleh guru kepada murid), memperoleh talqīn merupakan beberapa tradisi yang mereka pertahankan.

Secara spiritual, seorang mursyid memiliki wewenang untuk membaiat para muridnya untuk menjadi penerus kepemimpinannya. Mereka berhak memilih murid yang memiliki kualitas yang dianggap cukup. Ada banyak cara menentukan suksesor (penerus), tiap-tiap tarekat memiliki tradisi yang berbedabeda. Para murid yang telah mendapatkan mandat dari sang mursyid akan memperoleh gelar khalifah. Biasanya dalam tradisi tarekat tertentu yang bersangkutan akan mendapatkan tambahan nama seperti "din" seperti Jalaluddin, Nizamuddin, Muinuddin, dan sebutan lainnya.

Sistem relasi antara shaikh dengan murid menjadi jangkar dalam tarekat. Terjaganya solidaritas ini karena adanya beberapa ajaran nilai dan ritual yang diwariskan secara turun temurun. Salah satu di antaranya, ajaran tentang șuhbah, yakni sistem relasi antara guru dan murid dalam hubungan spiritual dan sosial. Ketika relasi tersebut sudah terjalin dengan baik, maka yang perlu diamalkan oleh para murid adalah tentang wasillah dan rābițah. Artinya, rābitah

397̣āhir, al-Taṣawwuf: al-Mansha wa al-Maṣdar, 186.

JURNAL THEOLOGIA — Volume 30, No. 2, December 2019 
tidak diartikan sebagai cara berhubungan secara eksklusif antar anggota dalam komunitas tarekat tetapi adanya penjejangan dan klasifikasi dalam menjalin relasi dan hubungan antara guru dan murid.

Dengan ungkapan lain, dalam setiap tarekat terdiri dari mursyid dan doktrin atau ajaran yang selalu dipegang teguh sehingga lingkaran kerajaan spiritual mereka tetap terjaga dengan baik, bahkan di tengah gempuran arus peradaban yang semakin maju sekalipun. Keberadaan seorang mursyid dalam suatu tarekat adalah kunci. Ia memegang andil yang besar dalam proses perjalanan spiritual murid-muridnya. Hampir seluruh organisasi tarekat, memposisikan seorang mursyid sebagai tokoh sentral yang darinya mewarisi silsilah keilmuan. Silsilah ini kemudian terus dipegang secara turun temurun dari mursyid ke murid lalu berlanjut ke generasi berikutnya. Maka, pada titik inilah, mursyid memegang otoritas penuh dalam berbagai laku spiritual baik dalam bentuk ritual maupun yang lainnya.

\section{E. Konstruksi Sosiologis Karisma Mursyid}

Betapapun mursyid dalam kacamata teologis sebagai figur yang dianggap sebagai penerus Nabi namun hal tersebut tidak dapat dilepaskan dari tinjauan secara sosiologis. Kepatuhan para murid tidak selalu karena motif kesadaran bahwa mereka adalah orang-orang yang memang secara spiritual diyakini sangat mumpuni namun ada faktor-faktor penunjang lain yang menguatkan.

Karisma, sebagaimana diteorikan oleh Weber menjadi kerangka yang menarik untuk melihat fenomena ini. ${ }^{40}$ Benarkah mursyid memiliki otoritas begitu tinggi karena karisma yang dimiliki? Mustafa melihat bahwa karisma seorang mursyid menempati posisi yang penting. Menurutnya, unsur penting yang dapat menopang karisma adalah kewibawaan. Karisma seorang mursyid tidak akan diperoleh tanpa adanya kewibawaan yang dimiliki. Kewibawaan sendiri dapat terbentuk dari dua kemungkinan. Pertama, berupa anugerah Tuhan baik secara biologis maupun psikologis, seperti perawakan yang gagah, suara yang tegas, dan cara komunikasi yang elegan dan bijaksana. Kedua, karena ikhtiar dari sang mursyid sendiri. Yang kedua ini lebih bersifat rekayasa. Dengan

\footnotetext{
40Max Weber, Economy and Society: An Outline of Interpretative Sociology (Barkeley: University of California Press, 1978), 81.
} 
kata lain, sang mursyid melakukan ikhtiar untuk menjadi pribadi yang șālih, memiliki wawasan yang luas, serta kelebihan-kelebihan lain yang diusahakan. Biasanya yang terjadi dalam tradisi tarekat para murid mengikuti jejak para murād (shaikh) dalam hal apapun. ${ }^{41}$

Identitas intelektual berupa karamah yang dimiliki mursyid pada satu sisi, secara historis telah mereproduksi dan mereformulasi kepercayaan yang kuat dalam konteks yang spesifik. Terhadap setiap pengikut, mursyid dapat memainkan diskursus dominan yang pada gilirannya akan merefleksikan apa yang disebut Eyerman dan Jamison sebagai minat pengetahuan (knowledge interest) ${ }^{42}$ dari suatu pengikut ke generasi berikutnya.

Mengikuti pendapat Eyerman, peran dan mobilitas mursyid dapat dikelompokkan menjadi dua kategori. Pertama, mobilitas yang menginterpretasikan aktivis dalam kerangka karakteristik-karakteristik personal, seperti mobilitas mursyid yang menjadikan berpikir sebagai kerja sekaligus memainkan fungsinya dalam mengatur segala hal, utamanya menjadi rujukan dari para pengikut. Kedua, mobilitas yang mengaitkan suatu struktur dengan fungsi sosial tertentu, dalam konteks ini, adalah mereka yang menciptakan, menyebarluaskan, dan menjalankan kebudayaan. Mursyid dengan kategori yang kedua inilah yang membedakan dengan aktivis pragmatis yang mengejar kepentingan sesaat. Mursyid dalam kategori ini bisa disebut sebagai mursyid yang memiliki mobilitas vertikal yang memiliki komitmen untuk menyelematkan dunia agar tidak menjadi penjara bagi individualitas dan menjadi kuburan bagi kebebasan. Dalam konteks yang lebih spesifik, mursyid kategori inilah yang dapat menjadi tumpuan para pengikut tarekat untuk terhindari dari tsunami informasi yang dusta, semburan berita bohong dari media sosial, dan pelbagai kemirisan

\footnotetext{
${ }^{41}$ Mustofa Mustofa, “Tinjauan Budaya Atas Kultur Tasawuf Berbasis Mursyid Perempuan,” ElHarakah: Jurnal Budaya Islam 10, no. 3 (2008): 259-71, https://doi.org/10.18860/el.v10i3.4762.

${ }^{42}$ Minat pengetahuan bisa didefinisikan sebagai jenis pengetahuan yang terbentuk dalam konteks sebuah generasi intelektual tertentu. Lihat: Larry Saha, "Book Reviews: Social Movement: A Cognitive Approach. Ron Eyerman and Andrew Jamison. London, Polity Press, 1991. 184pp. \$29.95 (paper)," The Australian and New Zealand Journal of Sociology 29, no. 1 (1993): 137-39, https://doi.org/10.1177/144078339302900110; R. Eyerman dan A. Jamison, Social Movements: A Cognitive Approach (London: Polity Press, 1991), 129-130; Sebagai perbandingan, Burke memandang bahwa ide-ide dapat tersituasikan (situated) secara sosial dan dibentuk oleh pandangan dunia (world views) atau gaya-gaya pemikiran (styles of thought). Gaya pemikiran ini berkaitan dengan periode dan generasi tertentu untuk mencipta sebuah genealogi. Lihat: P. Burke, A Social History of Knowledge: From Gutenberg to Diderot (Cambridge: Cambridge University Press, 2000), 70.
} 
lainnya di era pasca kebenaran (post-truth). Karisma yang diperankan oleh mursyid dalam konteks ini adalah sumbangsih signifikan meliputi pengejawantahan aktifitas bukan untuk mencapai tujuan-tujuan praktis.

Namun, mobilitas mursyid juga sangat ditentukan oleh komitmennya untuk mengartikulasikan gagasan-gagasan fundamental mengenai identitas dan nurani kolektif dengan jalan melembagakan dan menerapkan dalam praktik kesatuan antara kebenaran, nilai-nilai moral, dan penilaian estetis, yang semua itu diwujudkan dalam amaliah-amaliah tarekat. Dari perwujudan itu, mursyid memaksimalkan perannya dalam proses menyuarakan nurani untuk mengarahkan terciptanya tindakan kolektif berdasar norma yang berlaku.

Otoritas yang dimiliki oleh mursyid adalah otoritas karismatik yang akan direspon oleh para khalifah dan muridnya dengan mematuhi secara inspirasional. Mursyid memiliki otoritas karena pada dirinya melekat komponenkomponen penopang karisma sebagaimana tersebut di atas. Kepatuhan para murid karena sosok sang mursyid adalah figur yang inspiratif yang dapat dijadikan teladan. Apa yang diperintahkan oleh mursyid kepada murid hakikatnya telah dilakukan oleh mursyid ketika masih menjadi murid. Artinya, seorang mursyid lebih dulu memberikan contoh sebelum memerintah.

Pada faktor lain, otoritas mursyid juga terbentuk karena sejak awal sudah melalui pendidikan di zāwiyyah, dan telah dibaiat serta memiliki silsilah secara turun temurun. Mursyid dididik dalam model pendidikan yang kontinyu dan dalam format yang khas. Zāwiyyah, khānāqah, atau ribāț, adalah tempat-tempat penggemblengan kepribadian mereka. Artinya, karisma tersebut tidak muncul serta merta, melainkan melaui proses yang panjang dan dalam tempo yang tidak singkat.

Hal ini dipertegas oleh temuan Frembgen ketika meneliti aktifitas sufisme kontemporer di Pakistan. Ia menemukan bahwa seorang syaikh, atau yang lebih dikenal dengan wali mengkonstruksi dirinya dengan cara berapakaian yang khas, kemudian membuat tempat tersendiri untuk melakukan 'uzlah, dengan begitu sang mursyid semakin memiliki posisi yang begitu istimewa di hati para pengikutnya. Frembgen menyebut fenomena ini dengan sebutan legitimasi charisma of office ${ }^{43}$ (kharisma jabatan) sebagaimana teori Max Weber. ${ }^{44}$ Lebih-

${ }^{43}$ Stuart Clark, Thinking with Demons: The Idea of Witchcraft in Early Modern Europe (Oxford, New York: Oxford University Press, 1999), 686. 
lebih ketika sang mursyid dengan sengaja meniru semirip mungkin cara hidup gurunya, seolah ia mewarisi karisma yang dimiliki oleh gurunya. ${ }^{45}$

\section{F. Kesimpulan}

Mursyid dalam tradisi tarekat berfungsi sebagai penerus para Nabi. Mereka adalah para wali atau orang suci (saints) yang memiliki otoritas dalam olah rasa beragama, bahkan pada saat dan keadaan tertentu otoritasnya melampaui urusan agama, seperti sosial, ekonomi dan politik. Mursyid tidak membawa ajaran baru sebagaimana para Nabi namun mursyid memiliki wewenang untuk menafsirkan ajaran Islam dengan mata batin yang mereka miliki.

Mursyid sebagai rohaniawan dalam Islam sejak awal sudah terbiasa mengolah rasa sehingga tingkat spiritualitas mereka di atas rata-rata manusia. Mursyid digembleng dalam ikatan persaudaraan dalam kawah candradimuka yang bernawa ribāț, zāwiyyah, atau khānāqah. Tempat-tempat itu identik dengan tempat 'uzlah dan arena latihan ruhani para murid-murid sufi meskipun pada perkembangannya juga difungsikan untuk mengatur strategi peperangan, memusyawarhkan berbagai problem sosial dan kegiatan sosial lainnya.

Mursyid memiliki otoritas yang begitu kuat di tengah para pengikut karena mereka memegang tradisi secara turun temurun. Salah satu ajaran yang mashur dalam tradisi tarekat adalah șuhbah, yakni menjaga hubungan yang baik antar guru dan murid dan antar murid dengan manusia pada umumhya. Ada juga prosesi ba'iatyang bermakna sumpah setia murid terhadap gurunya.

Otoritas seorang mursyid tidak terlepas dari karisma yang terbentuk dalam dirinya. Karisma yang melekat pada mereka tidak dalam bentuk dan model yang sama. Ada yang secara genetis, mereka memiliki keistimewaan dan ada pula yang karismanya terbentuk karena diusahakan oleh sang mursyid sendiri. Dalam teori Webber, kharisma model ini disebut dengan karisma jabatan (charisma of office). Karisma yang melekat pada diri mursyid kemudian melahirkan kepatuhan inspirasional bagi para murid dan pengikutnya.

\footnotetext{
${ }^{44}$ Jennifer L Epley, “Weber's Theory of Charismatic Leadership: The Case of Muslim Leaders in Contemporary Indonesian Politics," International Journal of Humanities and Social Science 5, no. 7 (2015): 7-17, http://www.ijhssnet.com/journal/index/3137.

${ }^{45}$ Jurgen Wasim Frembgen, "From Dervish to Saint: Constructing Charisma in Contemporary Pakistani Sufism," The Muslim World 94, no. 2 (April 2004): 245-57, https://doi.org/10.1111/ j.1478-1913.2004.00050.x.
}

JURNAL THEOLOGIA — Volume 30, No. 2, December 2019 
Sedangkan peran dan mobilitas mursyid dapat dikelompokkan menjadi dua kategori. Pertama, mobilitas yang menginterpretasikan aktivis dalam kerangka karakteristik-karakteristik personal, seperti mobilitas mursyid yang menjadikan berpikir sebagai kerja sekaligus memainkan fungsinya dalam mengatur segala hal, utamanya menjadi rujukan dari para pengikut. Kedua, mobilitas yang mengaitkan suatu struktur dengan fungsi sosial tertentu, yaitu menciptakan, menyebarluaskan, dan menjalankan kebudayaan. Mursyid dalam kategori ini bisa disebut sebagai mursyid yang memiliki mobilitas vertikal yang memiliki komitmen untuk menyelamatkan dunia agar tidak menjadi penjara bagi individualitas dan menjadi kuburan bagi kebebasan.

Dalam konteks yang lebih spesifik, mursyid menjadi tumpuan para pengikut tarekat untuk terhindari dari tsunami informasi yang dusta, semburan berita bohong dari media sosial, dan pelbagai kemirisan lainnya di era pasca kebenaran (post-truth). Karisma yang diperankan oleh mursyid dalam konteks ini adalah sumbangsih signifikan meliputi pengejawantahan aktifitas produktif dan menghindari kuasa hoaks untuk membentuk daya pikir pengikut tarekat dalam mengidentifikasi kebenaran.[]

\section{DAFTAR PUSTAKA}

Ali, Mubarak. The Ulema, Sufis, and Intellectuals. Lahore: Fiction House, 2005.

Aqib, Abduloh Kharisuddin. "Kriteria dan Persyaratan Seorang Mursyid." Metafisika Center, 2018. http://www.metafisika-center.org/2018/03/ wali-mursyid.html.

Arberry, A. J. Sufism: An Account of the Mystics of Islam. New York: Routledge, 1950.

- - The Doctrine of The Sufis. Cambridge: Cambridge University Press, 1935.

Atjeh, Aboebakar. Pengantar Ilmu Tarekat (Uraian tentang Mistik). Solo: Ramadhani, 1985.

al-Bāqī, Muḥammad Fu’ād 'Abd. al-Mu'jam al-Mufahras li Alfāẓ al-Qur'ān al-Karīm. Kairo: Dār al-Ḥadīth, 1364.

Bruinessen, Martin van. “Tarekat dan Politik." Pesantren, 1992. 
Burke, P. A Social History of Knowledge: From Gutenberg to Diderot. Cambridge: Cambridge University Press, 2000.

Clark, Stuart. Thinking with Demons: The Idea of Witchcraft in Early Modern Europe. Oxford, New York: Oxford University Press, 1999.

Cook, Hannah L. "Liability: Avoiding the Lanham Act and the Right of Publicity on Social Media." The University of Chicago Law Review 83, no. 1 (2016): 457502.

Dallal, Ahmad S. "Sufism, Old and New: The Multiple Faces of the Spirit." Dalam Islam without Europe: Traditions of Reform in Eighteenth-Century Islamic Thought, 94-139. Chapel Hill: University of North Carolina Press, 2018. https://doi.org/10.5149/northcarolina/9781469641409.003.0004.

Daya, Burhanuddin. Agama Dialogis Merenda Dialektika Idealitas dan Realitas Hubungan Antar Agama. Yogyakarta: LKiS, 2004.

Dudung, Abdurrahman. "Gerakan Sosial-Politik Kaum Tarekat di Priangan Abad XX." Disertasi tidak dipublikasikan. PPs UIN Sunan Kalijaga, 2008.

Durkheim, Emile. The Division of Labor in Society. Illinois: The Free Press of Glencoe, 1960.

Dwyer, Peter D., dan Monica Minnegal. "Theorizing social change." The Journal of the Royal Anthropological Institute 16, no. 3 (2010): 629-45. https:// doi.org/10.2307/40926126.

Epley, Jennifer L. "Weber's Theory of Charismatic Leadership: The Case of Muslim Leaders in Contemporary Indonesian Politics." International Journal of Humanities and Social Science 5, no. 7 (2015): 7-17. http://www. ijhssnet.com/journal/index/3137.

Eyerman, R., dan A. Jamison. Social Movements: A Cognitive Approach. London: Polity Press, 1991.

Far, Seyyed Muhammad Rastgoo, dan Mahdi Dasht Bozorgi. "The Origin of Mysticism and Sufism in Hadith." Religious Inquiries 2, no. 3 (2013): 10317.

Frembgen, Jurgen Wasim. "From Dervish to Saint: Constructing Charisma in Contemporary Pakistani Sufism." The Muslim World 94, no. 2 (April 2004): 245-57.https://doi.org/10.1111/j.1478-1913.2004.00050x.

Fuller, Steve. Post Truth: Knowledge as Power Game. London: Anthem Press, 2018. 
al-Hifnī, 'Abd al-Mun'īn. al-Mausū'ah al-Ṣüfiyyah. Cairo: Maktabah Madbūlī, 2006.

Howell, Julia Day. "Indonesia's Urban Sufis: Challenging Stereotypes of Islamic Revival." ISIM Newsletter 6, no. 1 (2000): 17. /hdl.handle.net/10072/ 58807.

Khanafi, Imam. "Tarekat Kebangsaan: Kajian Antropologi Sufi terhadap Pemikiran Nasionalisme Habib Luthfie." Jurnal Penelitian 10, no. 2 (2013): 336-58. https://doi.org/10.28918/jupe.v10i2.367.

Massignon, Louis. Halläj: Mystic and Martyr. Terj. H. Mason. Princetown: Princeton University Press, 1994.

Mufid, Ahmad Syafii. Tangklungan, Abangan dan Tarekat: Kebangkitan Agama di Jawa. Jakarta: Yayasan Obor Indonesia, 2006.

Muḥammad, Yūsuf Khațtar. al-Mausū'ah al-Yūsufiyyah fi Bayāni Adillat al-Süfiyyah. Damaskus: Dār al-Taqwā, 2003.

Mustofa, Mustofa. "Tinjauan Budaya Atas Kultur Tasawuf Berbasis Mursyid Perempuan." El-Harakah: Jurnal Budaya Islam 10, no. 3 (2008): 259-71. https://doi.org/10.18860/el.v10i3.4762.

Nicholson, Reynold A. The Mystics of Islam. London: Routledge and Kegan Paul, 1975.

Riyadi, Agus. “Tarekat sebagai Organisasi Tasawuf (Melacak Peran Tarekat dalam Perkembangan Dakwah Islamiyah)." Jurnal At-Taqaddum 6, no. 2 (2014): 359-85. https://doi.org/10.21580/at.v6i2.716.

Saha, Larry. "Book Reviews: Social Movement: A Cognitive Approach. Ron Eyerman and Andrew Jamison. London, Polity Press, 1991. 184pp. \$29.95 (paper)." The Australian and New Zealand Journal of Sociology 29, no. 1 (1993): 137-39. https://doi.org/10.1177/144078339302900110.

Schimmel, Annemarie. al-Ab’ad al-Süfiyyah fi al-Islām wa Tārikh Tașawwuf. Terj. Muhammad Ismail Sayyid dan Ridha Hamid Qutb. Jerman: Al-Jamal, 2006.

_— Mystical Dimensions of Islam. Carolina: The University of North Carolina Press, 1975.

Schoenfeld, Eugen, dan Stjepan G. Mestrovic. "Durkheim's Concept of Justice and Its Relationship to Social Solidarity." Sociological Analysis 50, no. 2 (1989): 111-27. https://doi.org/10.2307/3710982. 
al-Shāfi'î, Muḥammad ibn Idrīs. al-Musnad. Beirut: Dār al-Kutub al-'Ilmiyyah, 1400.

Shamas-ur-Rahman, Ghulam. "Book Review: Sanusìyah: A Study of a Revivalist Movement in Islam, by: Nicola A. Ziadeh, Leiden: E. J. Brill, 1958.Pages. 148." AI-Ehsan, no. 2 (n.d.): 21-27.

Shihab, Alwi. Akar Tasawuf di Indonesia: Antara Tasawuf Sunni dan Tasawuf Falsafi. Tangerang: Pustaka IIMaN, 2009.

Thohir, Ajid. Gerakan Politik Kaum Tarekat: Telaah Historis Gerakan Politik Antikolonialisme Tarekat Qadiriyah-Naqsyabandiyah di Pulau Jawa. Ed. Dedi Ahimsa Riyadi. Bandung: Pustaka Hidayah, 2002.

al-Tirmidhī, Abu 'Īsā. Sunan al-Tirmidhī. Beirut: Dāl al-Fikr, 2005.

Trimingham, J. Spencer. The Sufi Orders in Islam. Oxford, New York: Oxford University Press, 1998.

Weber, Max. Economy and Society: An Outline of Interpretative Sociology. Barkeley: University of California Press, 1978.

Zāhir, Iḥsan Ilāhi. al-Taṣawwuf: al-Mansha wa al-Maṣdar. 1st ed. Lahore, Pakistan: Idārah Tarjaman al-Sunnah, 1986.

Ziadeh, Nicola A. Sanūsìyah:A Study of aRevivalist Movementin Islam. Leiden: Brill Archive, 1958. 
